\title{
O TERRITÓRIO NA TRANSIÇÃO DA PÓS-MODERNIDADE ${ }^{1}$
}

\author{
Paul Claval \\ Universidade de Paris-Sorbonne
}

Os geógrafos dos anos sessenta atribuíram tudo ao espaço. Hoje em dia, eles falam mais comumente de território. Essa mudança reflete em parte os debates epistemológicos internos à geografia. Ela é, sobretudo, testemunha de uma profunda transformação do mundo, e de uma mutação correlata das maneiras de compreendê-lo. Concorrem para isso, o declínio das ideologias de dominante econômica, tão populares durante os "Trinta Gloriosos", a atenção mais perspicaz dada à maneira pela qual os homens vivem o seu meio e a fragilização das identidades, desencadeada pelo declínio das filosofias da história que serviam para interpretar o mundo. A partir de agora é aos lugares e àquilo que os diferenciam que muitos se referem para dizer o que eles são e em que se distinguem uns dos outros.

\section{1- O Território: uma descoberta recente da geografia humana}

\subsection{Território, controle e poder}

a) A partir do início do século, os geógrafos são levados a falar de território na medida em que se voltam para os problemas de geografia política e tratam do espaço destinado a uma nação e estruturado por um Estado. Muitos problemas nascem do desajuste entre a distribuição das populações e os limites do Estado;

\footnotetext{
${ }^{1}$ Este artigo foi originalmente publicado na revista Géographies et Cultures n. 20, inverno 1996, Paris: L'Harmattan. Tradução e revisão de: Inah Vieira Lontra, Márcio de Oliveira e Rogério Haesbaert. Agradecemos as observações muito pertinentes de Cláudia Mara Costa Alves.
} 
outros resultam da dificuldade que alguns países têm de garantir sua segurança dentro dos limites impostos pelo povoamento do país; eles procuravam se atribuir fronteiras mais fáceis de serem defendidas, como rios ou cadeias de montanhas. Para justificá-las, os seus representantes declaravam que a natureza concedeu-lhes os limites do território nacional. O território, nestas concepções, resulta da apropriação coletiva do espaço por um grupo.

b) Jean Gottman aproveita ao mesmo tempo as abordagens da Geografia política e da geopolítica do período entre-guerras e do pensamento dos teóricos do Estado, quando associam a concepção moderna de território à de soberania (1973). Para que uma entidade política possa ter a experiência do caráter absoluto do poder, é preciso que ela não tenha concorrente, e que exerça um monopólio total sobre o espaço dado; ela é então soberana. A idéia de território está assim ligada à de controle, e a justifica.

Esta concepção de território emerge no século XVI e é teorizada pela primeira vez por Jean Bodin. A idéia de contrato social como foi formulada por Hobbes, torna-o uma das bases de todas as doutrinas políticas modernas. Tendo vivido a experiência do caos no qual o uso privado da violência mergulhava suas existências, os membros de uma comunidade decidem renunciar a um direito de efeitos perversos, e o concedem ao "Leviatã"; o Estado nasce deste ato, que lhe dá uma soberania total sobre o espaço, o qual a partir de então ele controla.

Ao território do Estado, tal como resulta da teoria política moderna, se opõem aqueles que refletem outras estruturas de poder. A prática feudal de um poder hierárquico, em que cada escala só dispõe de atributos limitados, alcançando uma estruturação de espaços que se encaixam ou se cruzam, não leva à geometria simples dos territórios na qual a prática internacional conduziu no início a Europa e, depois, o conjunto do mundo desde o século XVII.

c) Robert Sack (1986) propôs uma interpretação de territorialidade bem próxima à de Gottman, mas aplicável em todas as escalas. Quando você tem crianças, diz ele, você pode impedi-las de abrir uma ou outra gaveta do seu escritório, de brincar com o computador, com o telefone ou o fax, de pegar livros das estantes e de colocá-los em qualquer lugar. A lista de proibições pode se estender ao infinito, o que diminui o efeito e prejudica sua eficácia. Impedindo pura e simplesmente o acesso das crianças ao escritório, com menos despesas você alcançará o resultado desejado. $\mathrm{O}$ território nasce então das estratégias de controle necessárias à vida social - uma outra maneira de dizer que ela exprime uma soberania. A abordagem de Robert Sack adquire importância por salientar que a idéia de territorialidade se aplica a todas as escalas, desde uma peça num apartamento até a de um Estado. 


\subsection{Território e realidade social}

a) Um outro componente da idéia de território vem da etiologia animal. Os trabalhos do austríaco Konrad Lorenz (1973) e do holandês Nicolas Tinbergen (1967) descobriram o papel que representa a territorialidade na vida de várias espécies. Os espaços de vida aí são possessivamente marcados. No interior dos compartimentos assim delimitados, uma ordem hierárquica é instituída - uma pecking order, segundo a expressão inglesa, freqüentemente utilizada. Um macho geralmente as domina, afirma sua superioridade sobre os mais jovens durante confrontos que se sucedem periodicamente; ele elimina os eventuais concorrentes que ultrapassem os limites. A partir do controle do território, os grupos animais asseguram a sua reprodução e controlam seus efetivos.

As pesquisas dos etiologistas alcançaram um enorme sucesso entre todos aqueles que se interessavam pelos animais nos países de língua alemã ou inglesa ou na Escandinávia desde o pré-guerra. A idéia de transpor os ensinamentos da etiologia às sociedades humanas é então sugerida por alguns, como Konrad Lorenz (1973); mas foi no início dos anos sessenta que ela se popularizou através das publicações de Robert Ardrey (1966) ou de Desmond Movis (1969). Pareceu arriscado para a maior parte dos especialistas em Ciências Sociais a idéia de transferir de forma brutal os conhecimentos da Biologia ou das Ciências Naturais para os comportamentos humanos, mas é difícil não aceitar comparações entre os grupos de primatas e os ancestrais do homem.

Os geógrafos se recusaram a incorporar as lições de Tinbergen ou de Lorenz ao seu domínio, mas retiraram dos exemplos fornecidos pela etiologia a idéia de que é preciso se sujeitar aos meios colocados em prática para controlar o espaço, a fim de compreender o dinamismo das sociedades (MALMBERG, 1980). Por que a apropriação de uma certa extensão não seria necessária para o desabrochar de certas funções sociais?

b) O sucesso da geografia radical de inspiração marxista conduz, no início dos anos setenta, a uma estranha retórica sobre a criação do espaço; pela recusa em "naturalizar" os fatos sociais, fez-se da sociedade a realidade primeira. Ela não está mergulhada em um meio que, pelo menos em parte, a precedeu: ela o suscita e o molda.

Tais posições são insustentáveis para os que se dizem materialistas. Os geógrafos marxistas que se querem coerentes, rapidamente descobrem que é preciso deixar de falar de criação de espaço. O território lhes permite salvar a cena. É o que expressa o dicionário de geografia de Roger Brunet:

O território diz respeito à projeção sobre um espaço determinado de estruturas específicas de um grupo humano, que inclui a maneira de repartição e, gestão o ordenamento desse espaço.

(BRUNET et al., 1992:436) 


\subsection{Território, símbolos e representação}

a) A dimensão simbólica do território está efetivamente presente nos trabalhos dos geógrafos, desde pelo menos o período entre as duas guerras. Jean Gottman a sistematiza quando propõe, em 1952, fazer da análise das iconografias uma das bases da geografia política.

Os trabalhos de inspiração fenomenológica e humanista caminham no mesmo sentido. Eric Dardel acentua que, para as sociedades primitivas, a terra é poder pois ela é origem (é dela que procede toda a realidade), presença (é "no seu encontro como uma paisagem que se apresenta e se anuncia a ela que o presente se renova e se transmite como uma reserva oculta de vigor e de força" [DARDEL, 1990:69]), e força sobrenatural ("na base da geografia dos povos primitivos, há... um comportamento religioso, e é através desse valor sagrado que se manifestam os 'fatos' geográficos" [DARDEL, 1990:74]).

b) A dimensão simbólica do território torna-se um dos temas essenciais da geografia, no momento em que se desenvolvem as pesquisas sobre o espaço vivido nos anos de setenta e oitenta. Nos países anglo-saxônicos, refere-se ao sentido de lugar (the sense of place), e retoma-se a tradição vidaliana de análise da personalidade das construções geográficas. Estão atentos à maneira pela qual os topônimos são escolhidos e às significações que lhes são atribuídas.

Os lugares memoráveis (hauts lieux) retêm a atenção:

São os lugares de memória; seu valor simbólico é mais ou menos nobre, local, nacional, internacional, mundial, ou próprio à uma religião, à uma cultura; eles são freqüentemente fontes de identidade coletiva e também de atividades econômicas.

(BRUNET et al., 1992:232)

c) A geografia novamente se inclina sobre o sentido de enraizamento, sobre os laços afetivos e morais que os grupos tecem com o solo onde nasceram e estão sepultados seus antepassados.

O geógrafos se contentavam, no período entre as duas guerras mundiais, em sondar as almas e os corações dos cidadãos das nações modernas. Ao mesmo tempo os etnólogos descobriam laços análogos, mas freqüentemente mais fortes ainda nos povos primitivos. Os trabalhos de Elkin (1967) os enfatizavam. Os aborígenes australianos praticavam uma economia de caça e de coleta que deveria deixá-los indiferentes ao meio ambiente a partir do momento em que encontravam plantas úteis e caça. Tinham na realidade uma identificação tão profunda com os lugares de morada frequientados por seus ancestrais, no tempo mítico, que muitos se deixavam morrer quando se encontravam deslocados.

Os trabalhos de geografia tropical se aproximam, pouco a pouco, dos métodos usados pelos etnólogos: as permanências em campo são mais demoradas, a atenção 
dada às monografias de detalhe se torna maior. Não se trata mais de falar de pessoas das quais não se compreende a língua. Essas novas condições de pesquisa levam a resultados próximos àqueles que os etnólogos tinham obtido trinta anos antes, e que tinham contribuído substancialmente para a tomada de consciência de Eric Dardel - conhecimento este obtido através dos trabalhos do seu sogro, o pastor Laenhardt, e de Mircea Eliade, o grande historiador das religiões. Jean Pierre Raison (1977) fica fascinado, em Madagascar, com a incapacidade das culturas indígenas em se definirem sem referência ao espaço. Os grupos só existem pelos territórios com os quais se identificam.

Joël Bonnemaison (1986) descobre, em Vanuatu, uma realidade semelhante, e pacientemente desmonta o emaranhado de mitos que enraizavam os ancestrais vindos de piroga, muitos anos atrás, no espaço que ocupam hoje. Hongkey Yoon (1986) enfatiza que os conflitos entre a população de origem européia e os Maoris da Nova Zelândia resultam mais freqüentemente da relação diferente que os dois grupos mantêm com a terra: os primeiros (europeus) só vêem aí um bem que se modifica, como qualquer outro, enquanto que os segundos (Maoris) só existem pelo e para o lugar sagrado (o marae), onde se reúnem e dançam.

As sociedades geográficas, segundo a expressão forjada por Jean Pierre Raison, são excepcionais, mas os laços simbólicos que unem os grupos ao território parecem universais. $\mathrm{O}$ vocabulário ocidental diz: luta-se pela pátria, pela terra do pai, diz a etimologia, ou pela mãe-pátria, curiosa expressão pois queria que a terra do pai se tornasse nossa mãe. Como destacar mais fortemente o papel do enraizamento nas sociedades que proclamam em alto e bom tom que estão presas à mobilidade, que elas proclamam responsável pelo progresso?

d) A consideração da dimensão territorial traduz uma mutação profunda na abordagem geográfica: falar em território em vez de espaço é evidenciar que os lugares nos quais estão inscritas as existências humanas foram construídos pelos homens, ao mesmo tempo pela sua ação técnica e pelo discurso que mantinham sobre ela. As relações que os grupos mantêm com o seu meio não são somente materiais, são também de ordem simbólica, o que os torna reflexivos. Os homens concebem seu ambiente como se houvesse um espelho que, refletindo suas imagens, os ajuda a tomar consciência daquilo que eles partilham.

(O território) contribui, em compensação, (...) para fortalecer o sentimento de pertencimento, ajuda na cristalização de representações coletivas, dos símbolos que se encarnam em lugares memoráveis (hauts lieux).

(BRUNET et al. 1992:436).

Os geógrafos foram durante muito tempo bastante prudentes ao tratarem das realidades humanas. Eles se interessavam pelas diferenças objetivas de riqueza ou de status das pessoas, mas não se sentiam à vontade no momento em que alguém evocava as clivagens daí resultantes. O conceito de classe diante do qual tantas re- 
ticências se manifestavam, foi enfim adotado pela disciplina a partir dos anos cinqüenta na França, e desde os anos setenta no mundo anglo-saxônico, porém sem espírito crítico - adota-se sem esclarecer que a conscientização que cria a classe (ou qualquer outra categoria coletiva) implica, além da similaridade objetiva das situações, um sistema de comunicação bastante eficaz, para que cada um possa comparar seu status aos de outros membros do grupo. (CLAVAL, 1973).

O território aparece, deste ponto de vista, como essencial, oferecendo àqueles que o habitam, condições fáceis de intercomunicação e fortes referências simbólicas. Ele constitui uma categoria fundamental de toda estrutura espacial vivida, a classe espacial. Como para todos os fenômenos de classe, as hierarquias existem: diz-se "nós" para o bairro, o vilarejo, a pequena região ou a nação, conforme o contexto no qual alguém se encontra ou o tipo de jogo ao qual se assiste (CLAVAL, 1973).

\section{A contribuição dos trabalhos sobre a identidade.}

Só há pouco tempo as ciências do homem se apaixonaram pelos problemas de identidade: é pela psicanálise que, por volta da $2^{\text {a }}$ Guerra Mundial, começam as pesquisas neste domínio. A curiosidade se amplia bruscamente junto às ciências sociais nos anos setenta, no momento em que se começa a falar dos problemas de identidade como característicos das sociedades contemporâneas.

\subsection{Identidade e personalidade: a concepção essencialista do indivíduo e do grupo.}

A primeira corrente de pesquisa sobre identidade a coloca em relação com a idéia de personalidade. Erik Erikson (1972) se refere à crise da adolescência. Até essa idade, a sociedade espera das crianças que elas aceitem os modelos de comportamento que lhes são impostos de fora pelos códigos de gramáticas de comunicação que devem assimilar, pelas ordens que recebem, pelas interdições que lhes são determinadas e pelas regras de educação que os obrigamos a utilizar. A adolescência é um momento difícil porque os jovens devem aprender a contar apenas consigo mesmos, fazendo suas próprias regras a partir do que lhes foi ensinado, o que os obriga a tornar coerentes seu sistema de valores. Esse trabalho de interiorização e de hierarquização modela o caráter do indivíduo e o transforma em "pessoa".

$\mathrm{O}$ resultado dos ajustes que se desenvolvem assim, antes da entrada na idade adulta, e que os ritos de passagem formalizam, varia de uma cultura à outra. Aqui, admite-se que muitas das escolhas são ditadas do exterior, o que restringe consideravelmente a responsabilidade de cada um (HÉRITIER, 1977). Aliás, o que conta, sobretudo, é nunca perder de vista o interesse maior do grupo, do qual alguém é solidário - como nas morais de código de honra. Nas sociedades cristãs, no protestantismo em particular, o homem é livre e responsável pelas suas esco- 
lhas; é nesse caso e somente aí que o indivíduo merece respeito, é para ele que a noção dos direitos humanos foi imaginada e se encontra filosoficamente justificada. O marxismo e o freudismo insistem novamente sobre os condicionamentos externos do indivíduo, de sua própria classe ou impostos pela sociedade, através da imagem do pai no âmago de cada um. Para essas filosofias modernas, a pessoa deixa de estar ao lado da sociedade e da cultura: ela tem suas fontes na natureza e na espontaneidade que a educação e as convenções sociais reprimem.

A construção da identidade toma uma nova dimensão cada vez que os jovens têm a possibilidade de escolher entre vários sistemas de valores. Nem todos interiorizam as mesmas regras, os meios onde as culturas se misturam conhecem identidades sutis e estáveis. Daí as críticas que freqüentemente são dirigidas aos mestiços, nem sempre se sabe qual sistema de valores eles tornaram seu: se o do pai ou o da mãe. Acontece, então, nos momentos difíceis ou de crise, de trocarem de identidade.

As situações de contato são muito perigosas para a manutenção das identidades ao ponto das culturas há muito tempo expostas imaginarem sistemas que limitam a importância dos intercâmbios aos quais elas se entregam. A endogamia evita a mestiçagem biológica. As interdições alimentares proíbem o sentar à mesma mesa que o outro, ou o beber com ele.

A construção das identidades assume, desse ponto de vista, uma dimensão geográfica: um grupo preocupado em não ver suas novas gerações se afastarem dos ideais tradicionalmente professados tem interesse em viver isolado. Desse ponto de vista, a construção do território faz parte de estratégias identitárias.

\subsection{Identidade e alteridade: as concepções relacionais da identidade}

A identidade é realmente, sempre, o resultado daquilo que se é e das maneiras que nos são concedidas de sentir, reagir e agir? Não. Há uns vinte anos a ênfase recai habitualmente na natureza relacional dos sentimentos da identidade. É o olhar que os outros têm de você que o define.

Os historiadores contribuíram consideravelmente para fazer triunfar essas abordagens. Nas sociedades ocidentais, as agitações políticas e o crescimento da mobilidade freqüientemente questionaram as identidades tradicionais. Ser francês na França do Antigo Regime era estar ligado ao Rei. De acordo com as províncias, a relação era diferente em função do momento e das circunstâncias em que era feita a integração com o Reino. Não havia contradição alguma em se sentir ao mesmo tempo provençal e francês.

A Revolução rompe esses laços e acelera a mutação em direção à mobilidade. Um exemplo mostra isto. A França do Midi não existia antes de 1789: foi em seguida ao episódio revolucionário que as pessoas tomaram consciência da semelhança das pronúncias e das atitudes deste grande terço do país (MARTEL, 1987). Os estudos lingüísticos não tinham feito ainda progresso suficiente para atribui-los ao fato occitano. É das reações dos franceses do Norte frente a concidadãos 
falantes e comunicativos que surge a imagem do meridional, logo apropriada pelos habitantes do Midi. É pelo fato da psicologia da época atribuir facilmente a loquacidade aos efeitos do clima mais clemente e de um sol generoso que o Midi é apresentado como uma região ensolarada e exuberante. As pesquisas de Olivier Carbonnell (1987) datam muito bem a mutação que marca o nascimento do Midi.

Os trabalhos de Catherine Bertho (1980) sobre o nascimento da Bretanha são ainda mais conhecidos, embora caracterizem uma realidade mais complexa. A Bretanha é uma velha província que foi sempre muito ciosa de suas prerrogativas e sensível em relação a certas iniciativas parisienses.

O gênio da Bretanha, escrevia Michelet, é um gênio de indomável resistência e de oposição intrépida, obstinado, cego, testemunha Moreau, adversário de Bonaparte. A situação é ainda mais sensível na história da filosofia e da literatura.

(MICHELET, 1966:20)

Mas não é em torno desta imagem tradicional e lisonjeira, que reflete o modo pelo qual os bretões concebem a si mesmos, que os estereótipos modernos se construíram. O tipo popular do bretão vem de preferência do desenho animado de Bécassine e da reação dos parisienses confrontados com o afluxo de camponeses pobres, pouco instruídos, ignorando tudo sobre a cidade e partindo desajeitados e grosseiros. A identidade é construída a partir do olhar do outro. Os bretões, em contrapartida ao infortúnio, têm bom coração e possuem uma imagem que não os lisonjeia, mas da qual eles se dão conta que dela não podem se liberar.

\subsection{A natureza das identidades}

As análises da personalidade abordam esta questão sob o ângulo do indivíduo e da psicologia. As abordagens racionais nos lembram que o que está em jogo é, ao mesmo tempo, o eu e o nós, que não podem ser concebidos sem um olhar sobre os outros, e muito freqüentemente, sem o olhar dos outros.

A etnologia baseia-se na descentralização e na descoberta do que é estranho. Quem a pratica é necessariamente conduzido, através de suas experiências de campo, a se questionar sobre o que ele é, e a descobrir que sua própria identidade, que lhe parecia um bem natural, não é absoluta. Consiste em afirmar tudo que a reflexão dos antropólogos traz para a compreensão da identidade.

É por estar confrontado com as forças de alteridade que o indivíduo tem necessidade de identidade. Falando sobre os Samo, Françoise Héritier escreve:

Para existir, o homem deve vencer a indiferença de Deus, a impotência dos antepassados, a hostilidade da vegetação e da feminilidade. Ele só pode nascer verdadeiramente de 
uma tolerância da natureza e da feminilidade. Por isso é que as estruturas sociais são necessárias ao homem-vir. Sem elas não haveria existência. É um marco rigoroso, determinado para "fazer" o indivíduo como existente, se afirmando frente à hostilidade ou à indiferença da natureza que enobrece as mulheres, concebidas de forma antinômica como forças de morte (...). É neste sentido que a socialização, questão masculina, existe para dar ao homem em grupo, negado enquanto indivíduo, uma verdade e uma identidade cuja função é tanto conter quanto tornar possíveis as forças incontroláveis.

(HÉRITIER, in LÉVI-STRAUSS, 1977:70-71)

A identidade aparece como uma construção cultural. Ela responde a uma necessidade existencial profunda, a de responder à questão: “quem sou eu?" Ela o faz selecionando um certo número de elementos que caracteriza, ao mesmo tempo, o indivíduo e o grupo: artefatos, costumes, gêneros de vida, meio, mas também sistemas de relações institucionalizadas, concepções da natureza, do indivíduo e do grupo, como lembra Françoise Héritier a respeito dos Samo. Os traços que caracterizam as pessoas são tão numerosos que somente uma parte é retida para definir a identidade. Isto significa que, a partir da mesma situação, outras conceitualizações seriam possíveis. Mas a identidade, uma vez definida, contribui para fixar a constelação de traços que ela reteve, e subtraí-los dos desgastes do tempo.

Através do testemunho dos antropólogos se desenha a idéia de que a identidade deve ser analisada como um discurso que os grupos têm sobre eles mesmos e sobre os outros, para dar um sentido à sua existência. Este se apóia sobre traços bem reais da vida material, da organização social e do universo dos valores da coletividade, mas é uma construção por natureza arbitrária. Isto explica que os termos aos quais ela recorre sejam sempre impostos pelos outros e interiorizados e valorizados como desafio.

A identidade é uma noção elusiva. Denis-Constant Martin destaca muito bem:

A dificuldade com a qual se depararam as ciências sociais consistiu, provavelmente, no que elas chamaram a identidade a propósito de certos fenômenos, caracterizando-a por uma falta, uma ausência, um defeito: Erik Erikson fala de busca; Claude Lévi-Strauss fala de morada virtual; Lucian Paye, de crise e Jacques Berque de horizonte.

(MARTIN, 1994:18)

Claude Lévi-Strauss é também muito explícito:

(...) a identidade é uma espécie de morada virtual, à qual nos é indispensável referir para explicar um certo número de coisas, mas sem que ela tenha jamais uma existência real.

(LÉVI-STRAUSS, 1977:332) 


\subsection{Identidade, temporalidade e territorialidade}

A identidade implica referentes sem os quais ela não poderia ser definida. "A narrativa identitária reconstrói quatro pilares da experiência humana: o tempo, o espaço, a cultura e os sistemas de crença”, escreve Denis-Constant Martin. Ela necessita do tempo para provar a seriedade das reconstituições que ela propõe:

A unidade diante do acontecimento, a coesão necessária à ação face ao Outro que foi definido devem estar enraizadas no passado. Convém recriar a história, 'inventar as tradições' (HOBSBAWM e RANGER, 1983) para demonstrar que a comunidade foi em todos os tempos organizada dessa forma e que (...) um passado glorioso lhe dá o direito de esperar um futuro feliz, e de lutar para desfrutá-lo. (MARTIN 1994:25)

O sentimento identitário permite que se sinta plenamente membro de um grupo, dotá-lo de uma base espacial ancorada na realidade:

A memória se constitui nos 'lugares', nas 'porções de natureza' em que estão enraizados os seus potenciais, dizia Jacques Berque (BERQUE, 1970:478) e a relação tecida entre a história e o espaço fornece uma base aparentemente material à identidade: ela lhe proporciona um território. A ocupação, conduzindo o trabalho da sensibilidade sobre o enraizamento físico, confere aos 'pays', às cidades, aos bairros, uma dimensão simbólica (...), uma qualidade que secreta o apego.

(MARTIN, 1994:25-26)

Vê-se, então, porque os problemas do território e a questão da identidade estão indissociavelmente ligados: a construção das representações que fazem certas porções do espaço humanizado dos territórios é inseparável da construção das identidades. Uma e outra, estas categorias são produtos da cultura, em um certo momento, num certo ambiente: os dados objetivos permitiriam, no mesmo quadro, definir outras identidades e outros territórios. Como todas as construções, elas podem ser colocadas em questão, e por vezes o são - há crises identitárias que provocam freqüentemente uma modificação da relação com o espaço: as transformações da realidade espacial correm o risco de provocar, ao contrário, um questionamento das construções identitárias; elas devem ser reformuladas ou reconstruídas sobre novas bases.

O suporte territorial identitário mais simples é aquele que é exclusivo e se apresenta em um só bloco: é o das sociedades geográficas de que falamos anteriormente. Em tais contextos o espaço e as identidades são realidades claramente definidas. Cada grupo pode se desenvolver num espaço em que ele se livra dos riscos de poluição de que o outro é portador. Mas tais situações seriam insustentáveis sem ordenamentos (aménagements), pois elas tornariam impossível todo contato e todo intercâmbio entre os grupos: elas condenariam a humanidade a viver somente sob o signo da hostilidade ou da indiferença. A trama dos territórios é, portanto, interrompida por movimentos de status duvidoso, mas onde os grupos 
se encontram, ou por lugares neutros onde as relações se tornam lícitas - os mercados com freqüência desempenham este papel, que pode também ser cumprido pelas áreas cerimoniais ou pelas peregrinações.

O suporte territorial das identidades não precisa ser contínuo e de um único bloco quando a construção do eu e do nós é menos frágil e não é ameaçada de dissolução ao menor contato: o que conta em tal caso é a dimensão simbólica de certos referentes espaciais, lugares de culto, túmulos de ancestrais. A territorialidade se exprime mais em termos de polaridade que de extensão. Nada se opõe, neste caso, a que os grupos de identidades diferentes se justaponham ou se imbriquem: sua co-habitação não provoca problemas de natureza política e religiosa na medida em que cada um dispõe de pontos de referência que o vincula a uma porção do espaço. As sociedades tradicionais oferecem múltiplos exemplos, no campo ou na cidade, de mosaicos territoriais estáveis.

Pode-se ter identidades sem referentes espaciais? Sim e não. A princípio, não: os grupos fragmentados sofrem de tal forma, por não disporem de referentes espaciais que garantam sua existência, que eles os criam no imaginário. Eles, às vezes, os situam no passado, na terra das origens, ou o projetam para o futuro, na terra prometida. Os judeus da diáspora diziam ritualmente: "O próximo ano em Jerusalém", o que era ao mesmo tempo lembrança e referência ao futuro.

As comunidades fragmentadas nem sempre se contentam com um centro simbólico próximo, campanário ou minarete, para se federar. Elas experimentam a necessidade de se fechar em micro-territórios dos quais elas saem somente para realizar o trabalho e as trocas que lhes permitem viver. Elas criam colônias, ou aceitam sem muito sofrimento ser fechadas em guetos, na medida em que estes lhes garantam sua identidade. $\mathrm{O}$ ideal, para muitos, não é se reunir para recriar uma grande unidade territorial, mas transformar o gueto em pequeno território inviolável - o que fazia, por exemplo, o shtetl dos antigos territórios do reino da Polônia-Lituânia (ERTEL, 1986).

No estágio seguinte, o território simbólico se torna móvel. É o caso de certos nômades que reconstituem o espaço sagrado que dá sentido a sua vida em todo lugar em que eles se instalam. Diz-se o mesmo para os judeus, para os quais o espaço territorial se reconstitui por toda parte em que estejam dadas as condições para que a Tora seja respeitada e louvada.

As construções políticas modernas, os Estados, nasceram da fusão de diversas populações. Elas precisaram renunciar, unindo-se, às territorialidades exclusivas que eram suas no passado, e precisaram aprender a viver com territorialidades polarizadas que permitem justaposições ou encaixes. Elas aprenderam a se identificar com construções territoriais mais vastas e com frequiência contínuas - o território nacional - mas também com símbolos que podem em todo lugar lembrar comunidades - caso da bandeira. 


\section{A identidade e o território na transição à pós-modernidade}

\subsection{A evolução das identidades e das territorialidades}

$\mathrm{Na}$ medida em que as identidades parecem feitas primeiro para afastar os indivíduos e os grupos dos golpes do tempo, elas não são fixas. Quando as pessoas fazem parte de vários grupos, lhes é possível requerer, segundo os momentos e as oportunidades, um ou outro dentre eles. A conversão faz romper com os elementos centrais do sistema de valores incorporados na identidade para substitui-los por outros.

Seríamos tentados a propor um esquema geral de evolução das identidades e das territorialidades: passaríamos então de construções culturais do eu e do nós percebidas como frágeis, e portanto plenas de territorialidades exclusivas e possessivas, para identidades fortemente estruturadas, mais resistentes aos contatos e aos intercâmbios e, portanto, mais facilmente associadas a territorialidades simbólicas, freqüentemente descontínuas, em mosaico ou encaixadas. A modernização das sociedades conduziria, após a uniformização das técnicas e das condições de vida e adoção de valores universais, à ampliação dos sentimentos identitários e ao triunfo da aldeia planetária. É um pouco neste sentido que se apresentavam tradicionalmente as reflexões sobre o território.

A observação incita à prudência. Nas grandes cidades que proliferam um pouco por todo canto, grupos de jovens se estruturam em gangues e tentam assegurar-se o controle exclusivo de territórios que eles defendem contra a penetração dos vizinhos. Nas sociedades camponesas tradicionais os jovens também lutavam, aldeia contra aldeia, para se afirmar, provar sua virilidade e mostrar sua capacidade de se impor frente aos outros. O progresso técnico tem os efeitos que se supõe? Neste caso, não.

A multiplicação dos deslocamentos e a rapidez das comunicações têm, contudo, efeitos incontestáveis sobre os sentimentos identitários. Quanto mais o universo no qual as pessoas vivem é limitado, mais a identidade é vivida sob a forma da necessidade: o indivíduo não vê como poderia se subtrair àquilo que o grupo do qual ele faz parte, e aqueles que se lhe opõem de forma permanente, lhe impõe como disciplinas, valores, modos de ser e imagens. A identidade está tão impregnada que ele não tem nenhuma necessidade de defini-la. Contenta-se em se opor aos outros, em dizer nós para todos aqueles que sente próximos, e em classificar o resto do mundo em algumas grandes categorias genéricas. Os seres que as compõem não têm o valor daqueles que fazem parte do grupo. São os glutões, os bárbaros. Eles pertencem a uma humanidade inferior, a uma sub-humanidade, ou são excluídos da humanidade. Na construção de suas identidades, elementos materiais, pertencimentos territoriais e valores são colocados sobre o mesmo plano.

A abertura da sociedade põe em causa estas certezas fáceis: ela multiplica os contatos com o Outro e mostra a sua complexidade e a sua diversidade. Esta con- 
frontação ampliada conduz com freqüência a atitudes defensivas: a afirmação identitária torna-se explícita. Para enfatizá-la, multiplicam-se os signos e investem-se os elementos objetivos de diferenciação de um valor simbólico novo. As sociedades camponesas européias reagem assim, durante o século XIX, à ameaça de dissolução nos grandes conjuntos anônimos - inventando novos vestuários, novos adornos de cabeça ou novas formas de arquitetura. Em menos de um século passa-se na Bretanha de menos de 10 tipos de toucas para mais de 100 (CRESTON, 1974)!

Tais estratégias deixam de ser aplicáveis quando o progresso prossegue e as áreas de circulação de bens e de pessoas se amplia. Com a industrialização, os utensílios se padronizam, as roupas são feitas dos mesmos tecidos e segundo modelos similares - a calça de blue jeans que se tornou o uniforme de uma parte da população mundial é uma prova.

Mas a dissolução das identidades tradicionais segue junto, no século XIX e durante a primeira metade do século XX, com a formação de identidades ampliadas, aquelas dos Estados nações que vêm ocupar toda a cena mundial. Indo no sentido da história, elas englobam, sem que em geral isto provoque dificuldades, o que subsiste de sentimentos de pertencimento e de territorialidades do passado. Estas deixam de ser vividas sob a forma de territorialidade contínua - e se transformam em territorialidades simbólicas que se prestam perfeitamente ao jogo de hierarquização e de imbricação dos pertencimentos.

\subsection{Da identidade à identificação}

Os referentes materiais que proclamavam as identidades e fixavam a natureza dos indivíduos e dos grupos deixam de se impor a cada um como necessidade. Nada obriga, é verdade, os jovens a se vestir em todo lugar da mesma forma - as escolhas que lhes são oferecidas nunca foram tão amplas. Tudo se passa como se parcelas imensas do universo material tivessem deixado de ser concebidas como suportes possíveis de identidade.

Contudo, a necessidade de se diferenciar não desaparece. Ela não é vivida da mesma maneira: o que vos opõe aos outros não vos é imposto pelo clima, pelo gênero de vida, pelas técnicas à disposição. A identidade deixa de se instituir sozinha, naturalmente. Aqueles que não querem ou não sabem fundar-se sobre uma construção rigorosa da pessoa são levados a procurá-la no universo dos objetos que os circundam (MAFFESOLI, 1978). A identidade é conferida pelo meio ou por alguns dos elementos do meio que nós escolhemos. Nós ingressamos num mundo de signos - e de consumo cultural (CLAVAL, 1980).

Aquele que deseja se afirmar compra uma casa antiga que ele restaura religiosamente respeitando as regras tradicionais de construção. Ele pavimenta o chão de ladrilhos antigos, percorre os antiquários para encontrar os móveis que estejam de acordo com a decoração assim elaborada. 
As estratégias de identificação são infinitas; é Michel Maffesoli (1988) que enfatiza assim a passagem entre as modalidades tradicionais da identidade e aquelas que nascem da universalização dos instrumentos da vida material, como também de sua diversificação. A identidade tradicional se inscrevia no registro da subordinação, do profundo e do autêntico. A preocupação de identificação que irrompe nas sociedades contemporâneas vem sobretudo do jogo e do arbitrário. Não se deve entretanto ser precipitado - ela testemunha a inquietude das pessoas que não sabem mais que sentido dar a suas vidas.

A transformação contemporânea dos sentimentos de identidade tem repercussões sobre a territorialidade: ela leva a uma reafirmação apoiada nas formas simbólicas de identificação. O sentido resgatado da festa o testemunha. As pessoas são mais sensíveis aos lugares e aos haut-lieux, o que não era o caso há uma ou duas gerações. $\mathrm{O}$ entusiasmo que conhece o patrimônio é um outro sinal destas transformações.

$\mathrm{Na}$ medida em que a identificação com os objetos fragiliza o indivíduo e o grupo, alguns pensam que é necessário consolidá-los através de medidas territoriais de exclusão.

\subsection{Fim da história, pós-modernidade e territorialidade}

As formas tradicionais de territorialidade não são questionadas apenas pela ocorrência da industrialização e do progresso dos meios de comunicação. Elas são profundamente afetadas pelo declínio ou pelo desmoronamento de uma parte das ideologias sobre as quais repousava nosso mundo. Os princípios sobre os quais repousavam as sociedades ocidentais perderam sua credibilidade: é isto que nos leva a dizer que vivemos a passagem para a pós-modernidade.

Os países do Leste tinham uma religião laica, o comunismo. Seu credo repousava sobre uma idéia simples: os homens podem e devem conhecer a felicidade à qual eles têm direito neste mundo e que lhes permitirá realizar-se plenamente. $\mathrm{O}$ desenvolvimento das forças produtivas levará a isso, com a condição de que o curso da história não seja desviado por modos de organização social e econômica defeituosos ou injustos - e com a condição, portanto, de que combatamos, destruamos e ultrapassemos o capitalismo.

O marxismo-leninismo é uma filosofia totalitarista da história, pois ela se arroga o monopólio do futuro. Ela oferece aos homens a única solução possível para ter acesso ao futuro radioso. Todas as outras formas de pensamento são recusadas ou combatidas: as religiões, porque elas dão receitas ilusórias de felicidade; o liberalismo, porque ele é somente a camuflagem dos interesses do capital.

O comunismo, assim, impedia as populações dos países do Leste de sonhar de outra forma além dos esquemas marxistas-leninistas. Uma derivação era entretanto tolerada: como as culturas populares eram tidas em alta estima, os diferentes povos 
constituintes da União Soviética ou da Europa do Leste eram convidados a se reconhecer em seus folclores. Os sentimentos nacionais se achavam, nessa ocasião, enaltecidos, mas fora de todo contexto histórico. Cada grupo tinha tendência a se identificar com os grandes momentos resgatados do passado. O território sonhado dos nacionalismos que desta maneira se formavam ultrapassava amplamente aquele que o grupo ocupa hoje. A história devia ser revista, para adequar a geografia dos territórios às aspirações dos grupos. Significava retornar a formas de territorialidade exclusivas que as filosofias da história tinham permitido ultrapassar em nome do universalismo.

O questionamento das filosofias da história foi particularmente brutal no mundo socialista, mas ela não poupa os países onde reinava o liberalismo. O fim da guerra fria torna manifesta uma evolução desencadeada há, pelo menos, uns cinqüenta anos. As sociedades desenvolvidas têm, todas, a partir de agora, regimes democráticos que nenhuma ideologia conclama a ultrapassar. Não se vê o que é possível fazer para tirar a vida da maior parte das pessoas da zona cinzenta em que ela hoje se inscreve.

A busca de identificação que destacamos anteriormente manifesta este desencantamento. É propício, como no Leste, à ressurgência de formas de territorialidade que se acreditava por um momento ultrapassadas.

\subsection{A proliferação dos discursos identitários}

O sentimento de identidade encontra-se em todas as épocas. A necessidade de falar dele é própria de alguns períodos, especialmente daqueles em que as certezas se desvanecem e em que a multiplicação dos contatos conduz as pessoas a duvidar daquilo que elas são. Denis-Constant Martin escreve:

O caráter recente d(a) literatura (sobre identidade) sugere que é no mundo contemporâneo que primeiro se deve estudar o que os textos designam por identidade: o mundo após a descolonização e o desmoronamento dos blocos, o mundo em reviravolta pelo surgimento, na cena internacional, de tantos novos Estados.

(MARTIN, 1994:18)

Nós vivemos num mundo em que as pessoas não sabem mais o que elas são, mas em que as facilidades de comunicação e de deslocamento multiplicam os pontos de referência em que podem se ancorar. Os valores outrora dominantes são erodidos, mas há hesitação sobre aqueles que poderiam substitui-los. As vias que podem seguir a reconstrução das identidades são múltiplas. É por isto que se fala tanto dela. A razão é simples, como sublinha Denis-Constant Martin:

(O indivíduo) pode então (...) mudar suas filiações e seus graus de pertencimento. 
A função do discurso identitário é de orientar estas escolhas, de tornar normal, lógico, necessário, inevitável, o sentimento de pertencer, com uma forte intensidade, a um grupo. Ele se dirige à emotividade, se esforça por impressionar, por emocionar, a fim de que este sentimento de pertencimento impulsione, caso a situação o exija, a agir: impelido pelo sentimento de pertencimento torna insuportável a recusa de defesa. A fim de criar as condições desta adesão, o discurso identitário tem por tarefa definir o grupo, fazer passar do estado latente àquele de 'comunidade' em que os membros são persuadidos a ter interesses comuns, a ter alguma coisa a defender juntos.

(MARTIN, 1994:23)

Quais são os efeitos das identidades que se procura, assim, suscitar?

Primeiramente, o discurso identitário classifica, define e leva a operar as escolhas. Ele deve permitir distinguir o um do Outro, de maneira a excluir o outro, a fazer dele responsável, um perigo... Esta distinção, esta divisão, penetra nas mentes, nas práticas - dos dois lados, pois designar um Outro é incitá-lo, constrangê-lo às vezes a aceitar esta alteridade e esta definição que é dada do exterior.

(MARTIN, 1994:24)

Os discursos identitários contemporâneos se pretendem militantes. Eles têm por finalidade extrair uma ordem do que é percebido como o caos. Os grupos que se formam esperam assim se livrar da inquietude ambiente, mas eles percebem sua empreitada ameaçada. Para levá-la a bom termo, não é suficiente demonstrar às pessoas que elas pertencem a um grupo unido. É preciso libertá-las das forças dissolventes que arriscariam arruinar a empreitada que estão executando.

Nada de surpreendente, então, em constatar que as identidades que se busca promover exigem territorialidades contínuas e absolutas: não se trata simplesmente de se afirmar; o objetivo é o de fugir do contágio dos modos de pensamento que se condena, do efeito arrebatador de comportamentos e atitudes que reprovamos moralmente, e da poluição à qual nos expomos ao permanecermos em ambientes impuros. Os discursos identitários contemporâneos proclamam assim a necessidade, para o grupo, de dispor de um controle absoluto do território que ele torna seu. Não lhe é suficiente dispor de um lar simbólico, de um pólo de adesão. É necessário isolar os outros. Os movimentos nacionalistas ou regionalistas reivindicam a constituição, em seu benefício, de novas entidades soberanas. As minorias urbanas manifestam a vontade de dispor de bairros em que elas farão reinar a ordem ao seu modo, sem recorrer à polícia e à justiça oficiais, às quais elas negam toda autoridade.

Denis-Constant Martin destaca, com razão, a distância entre o conteúdo explícito dos discursos identitários e as realidades que eles recobrem. A vontade de se isolar e de ignorar o Outro:

significa igualmente que por trás dos enunciados esforçamo-nos em procurar, ao contrário do que se afirma, estruturas relacionais e interativas, modalidades de gestão da 
mudança. E, certamente, a mudança nas relações ou, em outras palavras, a evolução de relações coletivas que, nas sociedades modernas, desde que elas tenham certa amplitude e condicionem o acesso aos recursos, se tecem em torno do poder.

(MARTIN, 1994:21-22)

A contradição é evidente entre a vontade manifesta de ignorar o mundo e a preocupação real de renegociar a sua posição com os outros ou com as autoridades oficiais. A posição fixada ignora, de fato, as necessidades da troca banal, das complementaridades econômicas. Nas reivindicações territoriais, não está prevista em parte alguma a instituição desses espaços de contato, estas áreas de neutralidade que tradicionalmente permitiriam aos espaços vizinhos se comunicar sem risco de serem desfigurados.

\section{Conclusão}

A organização da vida segundo as normas e os valores afirmados por uma cultura e a execução de sistemas de relações intitucionais que ela supõe não podem se fazer no vazio: eles se desenrolam no espaço e o pressupõem em todos os níveis. Ele lhes é necessário como suporte material e lhes fornece uma de suas bases simbólicas. A maior parte das estruturas conhecidas da vida coletiva se traduz através de formas de territorialidade.

Elas são variadas: vão da apropriação completa ao simples enraizamento simbólico, e, portanto, da divisão de unidades discretas e que se negam e se ignoram até a articulação em torno de focos aos quais se prendem as identidades. Se a territorialidade é indispensável à afirmação e à realização das formas de existência e de identidade coletivas, suas formas e suas modalidades são múltiplas.

A diversificação da humanidade e o enriquecimento coletivo global que daí resultam devem muito às estratégias de estruturação territorial e às modalidades de intercâmbio que geralmente os acompanharam: instituições de zonas neutras entre territórios independentes ou de áreas de encontro entre grupos justapostos e polarizados, sobretudo em torno de lugares de identidade e de memória.

A construção de territorialidades exclusivas implica uma apropriação global, exercício da soberania e execução de estratégias de controle. É desta maneira que uma nova forma de territorialidade exclusiva foi codificada no ínício dos tempos modernos: aquela do Estado. Ela construía espaços neutros - mercados ou enclaves extra-territoriais de embaixadas. Todo o sistema internacional de relações que conhecemos repousa sobre este modelo territorial e sobre a capacidade da sociedade nacional de ultrapassar formas de sociabilidade e de cultura que lhe eram pré-existentes e de englobar os territórios que lhe correspondiam (BADIE, 1995). 
A generalização das formas territoriais do Estado-nação se tornou universal com a descolonização. Mas este triunfo é ao mesmo tempo enganador e frágil: enganador, porque em muitos sistemas de novos Estados o território é apenas uma concha vazia, sem valor simbólico para a maior parte dos cidadãos; frágil, porque as filosofias sociais sobre as quais repousava a modernidade são hoje criticadas.

Esta erosão dos valores tradicionais se soma à mobilidade mais intensa e à facilidade das comunicações para criar situações profundamente novas para a imensa maioria da população mundial: aquela em que se abrem as oportunidades de escolher seus próprios valores e em que as identidades de outrora deixam de ser vividas como elementos de um destino dos quais não se pode fugir. A universalização dos modos de vida material e a ruína das filosofias da história criam um vazio. Frente à desordem que se segue (BADIE e SMOUTHS, 1992), as tentativas são inúmeras. Os discursos identitários se multiplicam. Quais serão seus efeitos sobre as estruturas territoriais e a organização do espaço? Eis aí um dos desafios essenciais que o mundo atual coloca para a geografia.

O interesse que suscita a noção de território, as novas formas de territorialidade e as geopolíticas que elas implicam é considerável. É explorando essas modalidades inéditas de relações dos grupos com o espaço que os geógrafos podem trabalhar positivamente por um mundo melhor e mais justo. A tarefa comporta, entretanto, um risco: aquele de participar do jogo de fabricações dos discursos identitários ao invés de lhes considerar a partir de um olhar crítico. O papel do intelectual não é o de forjar ideologias, mas o de desmontar seus mecanismos e o de fazer compreender para que elas servem e que perigos elas implicam.

\section{O TERRITÓRIO NA TRANSIÇÃO DA PÓS-MODERNIDADE}

Resumo: A Geografia Humana, que só recentemente desenvolveu maior interesse pelo território, associa-o, conforme as circunstâncias, às idéias de poder e controle, à natureza do laço social ou ao papel das representações simbólicas. O interesse das ciências sociais pelos problemas de identidade cresceu paralelamente ao interesse dos geógrafos pelo território: a identidade está vinculada à construção do "self" ou às relações com o outro, e permanece como uma noção elusiva. O território serve como uma base para sentimentos de identidade de diversos modos. A transição para a pós-modernidade desafia as forças por trás de identidades tradicionais, que induzem a uma busca de identificação para objetos ou paisagens. Isso provoca o fim das filosofias da História sobre as quais foram construídas as identidades e os territórios de outrora. A subseqüente proliferação de discursos identitários expressa o déficit de sentido de mundo de hoje e pode se revelar perigoso por suas conseqüências políticas.

Palavras-chave: Controle, História, Identidade, Alteridade, Pós-modernidade, Poder, "Self", Território.

\section{TERRITORY IN THE TRANSITION TO POSTMODERNITY}

Summary: Human geography, which developed only recently an interest for territory, links it, according to the circunstances, to the idea of power and control, the nature of social link, or the role of symbolic representations. The interest of social sciences for the problems of identity grew at the same time than that of geographers for territory: identity is linked to the construction of self or the 
relations with others, and remains an elusive notion. Territory serves as a basis for identity feelings according to variable modes. The transition to postmodernity challenges the forces behind traditional identities, which induces a frienzed quest of identification to things or landscapes. It provokes the end of the philosophies of history, upon which were built the identities and territories of yesterday. The ensuing proliferation of identitary discourses expresses the deficit of sense of the world of today, and may be dangerous through its political consequences.

Keywords: Control, History, Identity, Otherness, Postmodernity, Power, Self, Territory.

\section{Bibliografia:}

ANDERSON, B. (1983): Imagined communities. Reflections on the origin and spread of nationalism. Londres, Verso.

ARDREY, R. (1966): Le territoire. Une enquête personnelle sur les origines animales de la proprieté et des nations. Paris, Stock.

BADIE, B. (1995): La fin des territoires. Essai sur le désordre international et sur l'utilité sociale du respect. Paris, Fayard.

BADIE, B. e SMOUTS, M (1992): Le retournement du monde. Sociologie de la vie internationale. Paris, Presses de la Fondation Nationale des Sciences Politiques et Dalloz.

BERQUE, J. (1970): Qu'est-ce qu'une identité collective, p. 11-18. In: Pouillon, J. e Miranda, P. (dir.) Echanges et communications. Mélanges offerts à Claude Lévi-Strauss à l'occasion de son 60e. anniversaire. Haia, Paris, Mouton.

BERTHO, C. (1980): L'invention de la Bretagne. Genèse sociale d'un stéréotype. Actes de la recherche en sciences sociales, vol. 35, p. 45-62.

BONNEMAISON, J. (1986): Les fondements d'une identité. Territoire, histoire et société dans l'archipel du Vanuatu. Paris, ORSTOM, 2 vol.

BRUNET, R. et al. (1990): Les mots de la Géographie. Dictionnaire critique. Paris, Montpellier, La Documentation Française. Reclus.

CARBONNELL, Ch.-O. (1987): Midi, histoire d'un mot. Midi, Revue de Sciences Humaines et de la littérature de la France du Sud, p. 11-24.

CLAVAL, Paul. (1979): Régionalisme et consommation culturelle. L'Espace Géographique, vol. 8, n. 4, p. 293-302.

CRESTON, R.Y. (1974): Le costume breton, Paris.

DARDEL, E (1990): La Terre et l'Homme. Paris, C.T.H.S.: 1a. ed. 1952.

ELKIN, A.P. (1967): Les aborigènes australiens. Paris, Gallimard: 1a. ed. 1938

ERIKSON, Eric. (1972): Adolescence et crise. La quête de l'identité. Paris, Flammarion: 1a. ed. 1968.

ERTEL, Rachel. (1986): Le Shtetl. La bourgade juive de Pologne. Paris, Payot. GOTTMANN, Jean. (1952): La politique des Etats et leur géographie. Paris, A. Colin. 1973. The significance of Territoiry. Charlottesville, Va. University of Virginia Press. 
HÉRITIER, F. (1977): L'identité samo, p. 51-72 de: Claude Lévi-Strauss (dir.). L'identité. Paris, PUF.

HOBSBAWM, E. Ranger, T. O. (eds.) (1983): The invention of tradition. Cambridge, Cambridge University Press.

LÉVI-STRAUSS, C. (dir.) (1977): L'identité. Paris, PUF.

LORENZ, K. (1973): Evolution and modification of behaviour. Chicago, University of Chicago Press. 1a. ed.:1965.

MAFFESOLI, M. (1988): Le temps de tribus. Le déclin de l'individualisme dans les sociétés de masse. Paris, Méridiens Klincksieck.

MALMBERG, T. (1980): Human Territoriality. New York, La Haye. Paris, Mouton.

MARTEL, P. (org.) (1987): L'invention du Midi. Réprésentations du Sud pendant la période révolutionnaire. Aix-en-Provence: Edisud.

MARTIN, D.-C. (1994): Identités et politique: récit, mythe et idéologie. p. 13-38 de: Martin, D.-C. (org.) Cartes d'identité. Comment dit-on "nous" en politique. Paris, Presses de la Fondation Nationale es Sciences Politiques.

MICHELET, J. (1966): Tableau de la France. Paris, Hermés-Waleffe: 1a. ed., 1833.

MORRIS D. (1969): Le singe nu. Paris, Grasset.

RAISON, J.-P. (1977): Perception et réalisation de l'espace dans la société Mérina. Annales, E.S.C. n. 3, p. 412-432.

SACK, R. (1986): Human Territoriality. Its theory and history. Cambridge, Cambridge University Press.

THUAL, F. (1995): Les conflits identitaires. Paris, Ellipses.

TINBERGEN, N. (1967): La vie sociale des animaux: introduction à la sociologie animale. Paris, Payot.

YOON, H.-K. (1986): Maori Mind. Maori Land. Berne, Peter Lang. 